\title{
Synthesis and Characterization of Silica Core/Multilayered Cobalt Ferrite-Silica Shell Particles for Lipase Immobilization
}

\author{
Milan P. Nikolic ${ }^{a *}$ (D), Katarina V. Pavlovićb ${ }^{b}$ Slobodanka Stanojević-Nikolića (D), Aleksa Maričićc \\ Vladimir $\boldsymbol{V}$. Srdic ${ }^{d}$ \\ ${ }^{a}$ University of Kragujevac, Faculty of Agronomy Čačak, Laboratory for Technological Processes \\ Control and Sustainable Development, Department of Food Technology, Čačak, Serbia. \\ ${ }^{b}$ University of Belgrade, Faculty of Biology, Serbia. \\ 'University of Kragujevac, Faculty of Technical Sciences Čačak, Joint Laboratory for Advanced \\ Materials of SASA, Section for Amorphous Systems, Čačak, Serbia. \\ ${ }^{d}$ University of Novi Sad, Faculty of Technology, Department of Materials Engineering, Novi Sad, Serbia.
}

Received: March 14, 2021; Revised: July 24, 2021; Accepted: August 12, 2021

\begin{abstract}
Multilayered core/shell particles were prepared by four-step deposition of cobalt ferrite layers and then deposition of external silica layer on the surface of silica core particles. The ferrite nanoparticles were obtained by co-precipitation of $\mathrm{Co}^{2+}$ and $\mathrm{Fe}^{3+}$ ions at $\mathrm{pH}=11$ and $\mathrm{pH}=15$, respectively. The agglomerated silica core/cobalt ferrite shell particles were obtained at extremely basic $\mathrm{pH}(\mathrm{pH}=15)$, while at $\mathrm{pH}=11$, monodispersed and non-aggregated core-shell particles were obtained. The poly(diallyldimethylammonium chloride)-functionalized silica core/ferrite shell particles were used as templates for deposition of mesoporous silica layers (obtained by neutralization of highly basic sodium silicate solution). The obtained porous multilayered core/shell particles were used as a host for covalent lipase immobilization inside the external silica layer. The initial activity of immobilized enzymes was about 13-fold lower than the native one, however, it showed good reusability and improved thermal stability compared to native ones.
\end{abstract}

Keywords:Core-shell, multilayered shell, magnetic properties, mesoporous silica, immobilization, lipase.

\section{Introduction}

Enzymes are versatile biocatalysts and have been used in a wide range of sectors including food ${ }^{1}$, textile ${ }^{2}$, ultrasensitive biosensing and development of pharmaceuticals ${ }^{3}$, fine chemicals and environmental engineering ${ }^{4}$. However, the application of natural enzymes is hampered by difficulties in reuse, product contamination and separation, as well as the poor catalytic efficiency and stored durability. These drawbacks can generally be overcome by immobilization of enzymes using various support materials and immobilization protocols 5 .

Recently, magnetic nanoparticles have attracted significant attention due to their large surface area, functionalizable surfaces, easy separation using external magnetic field, super paramagnetic property and low toxicity ${ }^{6}$. Significant progress has been made in order to develop new biocatalytic systems based on immobilization of enzyme or whole cells onto magnetic nanocarriers. The epoxy-functionalized magnetic nanoparticles were used as the carriers for immobilization of alcohol dehydrogenase, and immobilized enzyme retained $84 \%$ initial activity after five cycles ${ }^{7}$. Dopamine functionalized $\mathrm{Fe}_{3} \mathrm{O}_{4}$ nanoparticles coated with oleic acid were used for immobilization of lipase from Thermomyces lanuginosus via covalent coupling ${ }^{8}$. It has been found that thermostability

*e-mail:milanik@kg.ac.rs of the immobilized lipase was 2.9-fold improved at $60{ }^{\circ} \mathrm{C}$, compared to the free enzyme's thermostability. Furthermore, more than $75 \%$ of the initial activity of the immobilized lipase was retained after ten repeated uses ${ }^{8}$. Also, magnetic nanoparticles used as a cofactor regeneration system were applied for immobilization of glycerol dehydrogenase and NADH oxidase, in order to efficently produce 1,3-dihydroxyacetone from inexpensive substrates ${ }^{9}$.

Furthermore, functionalized magnetic nanocarrier grafted with protein spacers can be used for immobilization of recombinant Escherichia coli harboring glycerol dehydrogenase using specific recognition ${ }^{10}$. Studies have shown that the obtained immobilized cell exhibited higher thermal stability compared to the free cell and after ten cycles, the immobilized cell retained $62 \%$ initial activity.

Magnetic nanoparticles may be organized in core-shell type structures, where the properties emerging from either the core or shell materials can be controlled ${ }^{11}$. The unique coreshell structures and synergetic effect obtained by combining properties arising from either core or shell materials make them important for application in diverse fields, among them, biocatalysis ${ }^{12-15}$. Magnetic $\mathrm{Fe}_{3} \mathrm{O}_{4}$ nanoparticles covered with $\mathrm{SiO}_{2}$ shell were used for covalent immobilization of lipase $^{12}$. Compare to the free enzyme, the immobilized lipase displayed higher relative activity in the range of $\mathrm{pH}$ 
from 7.0 to 9.5 and higher thermal stability at temperature range from 30 to $70^{\circ} \mathrm{C}$. The relative activity of immobilized enzyme was 5.8 fold higher than that of the free lipase at $70{ }^{\circ} \mathrm{C}$ after $10 \mathrm{~h}$ incubation ${ }^{12}$. Also, it has been found that monodisperse core-shell magnetic organosilica nanoflowers with magnetic core and flower-like organosilica shell, which posses radial-wrinkle and tunable perpendicular channels, can be used as a support for Candida antarctica lipase $B$ (CALB) covalent immobilization ${ }^{15}$. This study showed that the flower-like organosilica shell allowed high enzyme loading (93 mg/g $\left.\mathrm{g}_{\text {support }}\right)$, high specific hydrolytic activity $\left(22,700 \mathrm{U} / \mathrm{g}_{\text {support }}\right)$ and better $\mathrm{pH}$ stability than free CALB. The enzyme also retains $65 \%$ of initial activity after being incubated in cyclohexane at $60{ }^{\circ} \mathrm{C}$ for $96 \mathrm{~h}$, and retains $90 \%$ of initial activity after being stored at the room temperature for 42 days.

With these desired characteristics, the design of coreshell particles for lipase immobilization opens up a new way of improving the catalytic activity and stability of the lipases, providing a "shield effect" to protect immobilized enzyme from biological, thermal and chemical degradation and may have potential applications in various lipase-based industrial processes.

In our previous work, we have developed core-shell particles for enzyme immobilization composed of a dense silica core surrounded by a bilayered shell consisted of either internal ferrite layer and external mesoporous layer ${ }^{16}$ or of both silica layers ${ }^{17}$. In the first case, the inner ferrite layer was superparamagnetic and the external mesoporous silica layer was prepared for potential enzyme immobilization. In the second case, the internal silica layer was used as a host for lipase immobilization by a physical adsorption, while the external silica layer prevented lipase leaching. The internal ferrite layer obtained via a one-step deposition process was very thin giving the low magnetization in the applied magnetic field ${ }^{18}$. On the other side, the activity of lipase immobilized inside the bilayered shell was reduced due to diffusion resistance within the outer silica layer ${ }^{17}$.

In this research, four-layered and thick cobalt ferrite shell was deposited onto silica core particles by a four step deposition process. The external silica layer was deposited on the surface of four-layered ferrite shell and used as a host for covalent immobilization of lipase.

\section{Material and Methods}

\subsection{Preparation of silica core particles from TEOS}

Silica core particles (sample C) were synthesized using hydrolysis and condensation of tetraethylortosilicate dissolved in anhydrous ethanol and distilled water under basic conditions $\left(25 \% \mathrm{NH}_{3}\right.$, Merck). The sample was prepared using a molar ratio TEOS: $\mathrm{H}_{2} \mathrm{O}: \mathrm{NH}_{4} \mathrm{OH}=1: 40: 2$ and a TEOS concentration of $0.25 \mathrm{~mol} / \mathrm{l}$. The water-ethanol-ammonia mixture has been prepared by mixing pure water, pure ethanol and ammonia solution $(25 \%)$ and after the addition of TEOS, the product suspension was continuously stirred at room temperature for $1 \mathrm{~h}$. The resulting white precipitated powder was centrifuged and washed with distilled water until the effluent was free of $\mathrm{NH}_{4}$ groups, and finally dried at $120^{\circ} \mathrm{C}$ for 1 day.

\subsection{Preparation of four-layered silica core/ cobalt ferrite shell particles}

To enable incorporation of divalent metal ions (e.g. $\mathrm{Ni}^{2+}$, $\mathrm{Zn}^{2+}, \mathrm{Co}^{2+}$ ) into ferrite structure ${ }^{18}$, coprecipitation of $\mathrm{Fe}^{3+}$ and $\mathrm{Co}^{2+}$ ions was done at higher $\mathrm{pH}$ values $(\mathrm{pH}=11$ and $\mathrm{pH}=15$, respectively). In order to prevent self-aggregation process of ferrite particles obtained at high $\mathrm{pH}$, surface modification of ferrite particles with citric acid was also performed (using the total cations/citric acid molar ratio 1/1). Equimolar amounts of the precursors $\left(\mathrm{Fe}\left(\mathrm{NO}_{3}\right)_{3} \times 9 \mathrm{H}_{2} \mathrm{O}\right.$ and $\left.\mathrm{Co}\left(\mathrm{NO}_{3}\right)_{2} \times 6 \mathrm{H}_{2} \mathrm{O}\right)$ were dissolved in deionized water, stirred and heated for $10 \mathrm{~min}$ at about $80{ }^{\circ} \mathrm{C}$. To allow electrostatic deposition of generated ferrite nanoparticles on the surface of silica core particles, the latter were pre-functionalized with poly(diallyldimethylammonium chloride) (PDDA) (Figure 1a). The warm solution of nitrate ions obtained this way was slowly added into a stirred vessel containing PDDA-functionalized silica core particles dispersed in $0.5 \mathrm{~mol} / \mathrm{L}$ sodium hydroxide solution containing the sodium citrate (trisodium citrate equimolar amount relative to metal ions) having a constant $\mathrm{pH}$ value of 15 and 11 , respectively, and temperature of $80^{\circ} \mathrm{C}$ (Figure $1 \mathrm{~b}$ ). After addition of the last amount of nitrate ions, the reaction continued for $10 \mathrm{~min}$. In the case of sample obtained at $\mathrm{pH}=11$, the procedure was similar, except that the initial $\mathrm{pH}(\mathrm{pH}=11)$ was set by adding a small amount of sodium hydroxide solution during the addition of the nitrate solution into dispersion of silica core particles.

The resulted precipitated powders were centrifuged and washed with distilled water several times and finally dried at $100{ }^{\circ} \mathrm{C}$. To allow electrostatic deposition of the second cobalt ferrite layer on the surface of silica core/monolayered shell particles, the latter were functionalized with PDDA

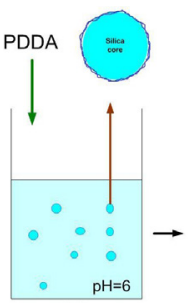

(a)

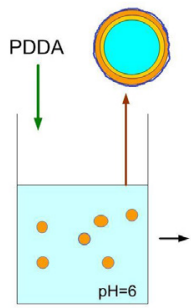

(e)

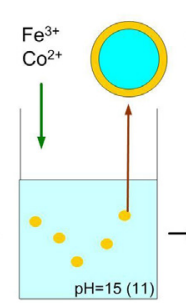

(b)

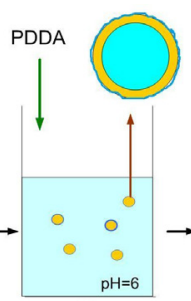

(c)

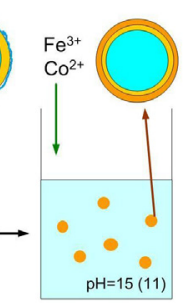

(d)
Figure 1. Preparation scheme of the bilayered silica/ferrite coreshell particles prepared at $\mathrm{pH}$ value of 15 (sample CF2-15) and 11 (sample CF4-11), followed by PDDA functionalization at $\mathrm{pH}=6$. 
(Figure 2c). The functionalized silica core/monolayered shell particles were centrifuged and used as templates for deposition of the second cobalt ferrite layered (Figure 2d) prepared as discussed above. The process of deposition of ferrite nanoparticles at $\mathrm{pH}=11$ was repeated 2 more times, while, between each deposition, the functionalization of obtained ferrite shells by PDDA was preformed (Figure $2 \mathrm{e}-\mathrm{h}$ ).

\subsection{Deposition of silica shell onto silica corel ferrite shell particles}

The silica core/four-layered ferrite shell particles (sample CF4-11) were used as templates for assembling the silica layer, which was composed of silica nanoparticles. To allow the electrostatic assembling of the silica layer on the surface of silica core/four-layered ferrite shell particles, the latter were functionalized with PDDA (Figure 2a). The PDDA-functionalized silica core/four-layered ferrite shell particles were prepared by dispersing $0.4 \mathrm{~g}$ silica core/four-layered ferrite shell in $40 \mathrm{ml}$ PDDA solution (at a concentration of $6 \mathrm{mg} / \mathrm{ml}$ ), which also contained $0.02 \mathrm{M}$ $\mathrm{NaCl}$. The suspension has been stirred for 1 hour at room temperature. The modified particles (sample CF4p) were centrifuged and successively washed with distilled water. These particles were dispersed in highly basic sodium silicate solution having a $\mathrm{Na}_{2} \mathrm{O} / \mathrm{SiO}_{2}$ molar ratio of 0.4 and a $\mathrm{SiO}_{2}$ concentration of $1.25 \mathrm{~mol} / \mathrm{L}$ (Figure $2 \mathrm{~b}$ ). The weight ratio between the silica core/ferrite shell particles (sample CF4-11) and silica from sodium silicate was 2. Sulfuric acid $(1 \mathrm{~mol} / \mathrm{L})$ was slowly added to this well-stirred dispersion at $80^{\circ} \mathrm{C}$ to decrease the $\mathrm{pH}$ value to enable generation of silica nanoparticles and their deposition on the surface of the PDDA-functionalized particles (Figure 2c).

\subsection{Functionalization of the external silica layer}

To allow covalent immobilization of lipase onto the external silica layer, the samples were functionalized in two steps: functionalization of silica layer with APTES (3-aminopropyltriethoxysilane $)^{19}$ and grafting of amine groups functionalized silica layer with glutaraldehyde. The APTESmodified silica layer was prepared by dispersing the sample CF4-S ( $0.5 \mathrm{~g})$ in anhydrous acetone $(35 \mathrm{ml})$, adding $0.15 \mathrm{ml}$ APTES and stirring for $24 \mathrm{~h}$. The obtained particles were centrifuged, extensively washed with anhydrous acetone

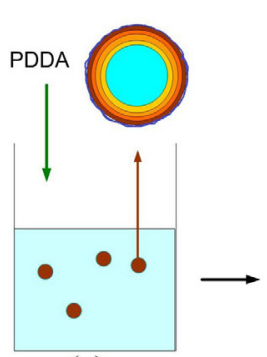

(a)

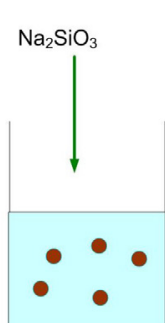

(b)

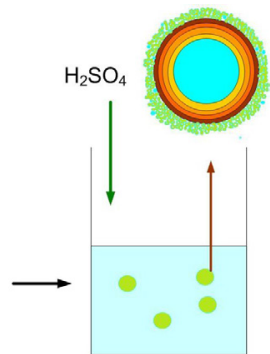

(c)
Figure 2. Preparation scheme of the assembling of silica layer on the surface of silica core/four-layered ferrite shell particles (sample CF4-S). and finally dried by removing excessive solvent at $80{ }^{\circ} \mathrm{C}$. Amine-modified silica layer was also activated with a $5 \%$ glutaraldehyde solution at $\mathrm{pH}=5.2$. The supports have been immersed in the glutaraldehyde solution for 1 hour at room temperature. The powder was centrifuged and washed four times with water to remove all remaining excess of unreacted glutaraldehyde.

\subsection{Immobilization of lipase onto external silica layer}

The covalent immobilization of lipase from C. rugosa (Sigma-Aldrich) onto the functionalized mesoporous silica layer was performed according to the following procedure: $0.33 \mathrm{~g}$ of functionalized core-shell particles and $25 \mathrm{ml}$ of lipase solution $(0.06 \mathrm{mg} / \mathrm{ml})$ in phosphate buffer $(0.05 \mathrm{M}$ and $\mathrm{pH}=7.0$ ) were added to a flask and stirred magnetically for $2 \mathrm{~h}$ at ambient temperature (Figure $3 \mathrm{a}$ ). The pore dimensions allowed immobilization of the enzymes inside inter-particle pores formed by aggregation of primary silica nanoparticles (Figure $3 b$ ). The reaction mixture was centrifuged and the supernatant was used for determining the amount of lipase remaining in the solution.

The concentration of lipase solution was measured by the Bradford method ${ }^{20}$, with BSA (bovine serum albumin) as a standard at $595 \mathrm{~nm}$.

\subsection{Characterization of particles}

The size and morphology of the particles were examined using a scanning electron microscope (SEM, JSM-6390 LV JEOL, operating at $30 \mathrm{kV}$ ) coupled with EDS (Oxford Instruments X-MaxN). Prior to SEM imaging, the samples were sputtered with gold. TEM characterization was performed using a JEM 1400-Plus JEOL device operating at $120 \mathrm{kV}$. The specific surface area (according to the BET method), pore size distribution (according to the BJH method) and pore volume of as-synthesized silica particles were measured by low-temperature nitrogen adsorption using a Quantachrom Autosorb-3B instrument. The zeta potential of particles was measured by dynamic light scattering (Zetasizer Nano ZS, Malvern Instruments). X-ray analysis of powders was performed using a Rigaku MiniFlex600 diffractometer

a)

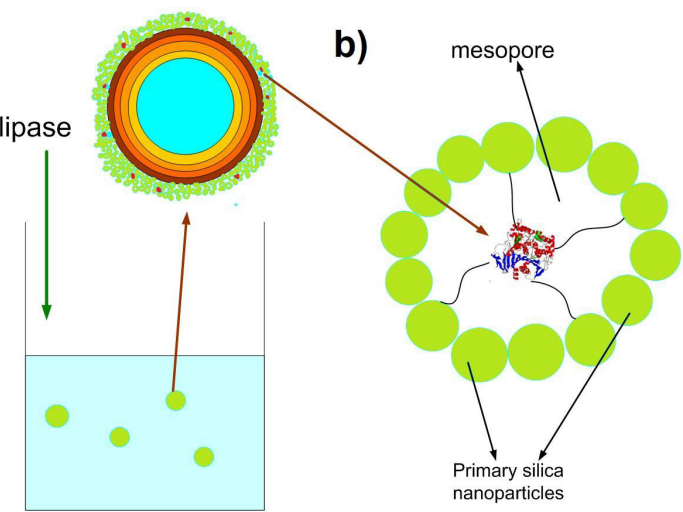

Figure 3. Immobilization scheme: a) immobilization of lipase (red dots) into external mesoporous silica layer; b) covalently bounded lipase inside interparticle mesopore. 
(CuKaradiation, $\lambda=1.5406 \AA$ ). X-ray diffraction patterns were recorded in the range of $10-80^{\circ}$, with a scan rate of $0.03^{\circ} \%$ s.

Thermomagnetic measurements in air were conducted by Faraday method, which presumes the influence of the non-homogenous magnetic field (with an intensity of $\mathrm{H}_{\text {app }}=$ $50 \mathrm{kA} / \mathrm{m}$ ) on the magnetic sample during heating ${ }^{21}$. Before thermomagnetic measurements, the powder was pressed at pressure of $500 \mathrm{MPa}$ to produce specimen with radius of $8 \mathrm{~mm}$ and width $1.5 \mathrm{~mm}$.

\subsection{Activity assay of free and immobilized enzymes}

The immobilization efficiency (\%) of the enzyme was calculated using the equation:

Immobilization efficiency $=\frac{C_{i}-C_{f}}{C_{i}} \times 100$

Where $C_{i}$ and $C_{f}$ are the initial and final concentration of the enzyme, respectively.

The activities of the free and immobilized lipase were measured by monitoring the catalytic hydrolysis of 4-nitrophenyl acetate (pNPA) to 4-nitrophenol ${ }^{22}$. Due to poor solubility in water, pNPA was first dissolved in acetonitrile and then added to the phosphate buffer $(0.05 \mathrm{M}, \mathrm{pH}=7)$. Activity assays were carried out by adding $100 \mu \mathrm{L}$ of free enzyme solution (at a concentration of $0.016 \mathrm{mg} / \mathrm{ml}$ ) or $30 \mathrm{mg}$ of the enzyme-loaded material (the amount of bound enzyme on support CF4-S was $2.69 \mathrm{mg}$ per gram of support) to $10 \mathrm{ml}$ of lipase substrate (the concentration of 4-nitrophenyl acetate was $0.55,1.1,2.2,4.4$ and $6.6 \mathrm{mM}$ ) at $28^{\circ} \mathrm{C}$. The reaction time of the native and immobilized lipase was 5 minutes. Afterwards, the amount of 4-nitrophenol was determined spectrophotometrically at $410 \mathrm{~nm}$. Enzymatic activity was performed in three replicates. The negative control for the enzyme assay was prepared using the same procedure, but without enzyme.

The thermal stability of the immobilized and native enzymes was examined by incubating two types of enzymes (free and immobilized enzyme) in $0.05 \mathrm{M}$ phosphate buffer $(\mathrm{pH}=7)$ at 45,60 and $75^{\circ} \mathrm{C}$ for 10 minutes, respectively. To prevent degradation of $\mathrm{p}$-nitrophenyl acetate at elevated temperatures, the effect of thermal treatment on enzymatic activity was determined at $28^{\circ} \mathrm{C}$ and substrate concentration of $1.1 \mathrm{mM}$.

Desorption and leakage of immobilized enzymes was examined after the fifth cycle of reusability testing by mixing $30 \mathrm{mg}$ of reused CF4-S-E composite in $10 \mathrm{ml} 0.05 \mathrm{M}$ phosphate buffer.

The material was centrifuged and $0.5 \mathrm{ml}$ of supernatant was put into $10 \mathrm{ml}$ of lipase substrate (the concentration of 4-nitrophenyl acetate was $1.1 \mathrm{mM}$ ) at $28^{\circ} \mathrm{C}$ to examine the potential presence of the enzyme via substrate hydrolysis.

\section{Results and Discussion}

\subsection{Preparation of silica core/cobalt ferrite shell particles}

SEM and TEM micrographs of the particles obtained by coprecipitation of $\mathrm{Co}^{2+}$ and $\mathrm{Fe}^{3+}$ ions at $\mathrm{pH}=15$ onto PDDAfunctionalized silica core particles via two-step coating method (sample CF2-15) followed by functionalization of previously deposited ferrite layer with poly(diallyldimethylammonium chloride) (PDDA) are shown on Figure $4 \mathrm{a}-\mathrm{b}$, respectively. The micrographs show agglomerates with an average size of about $4 \mu \mathrm{m}$ (Figure 4a), composed from aggregated silica core/cobalt ferrite shell particles (Figure $4 \mathrm{~b}$ ). This indicates that nucleation and deposition of cobalt ferrite nanoparticles at extremely basic $\mathrm{pH}(\mathrm{pH}=15)$ accelerates the aggregation process.

Figure 5 shows the TEM micrographs of the silica core/ cobalt ferrite shell particles (samples CF1-11 and CF411 obtained by one-step and four-step layer deposition, respectively, at $\mathrm{pH}=11$ ). The obtained non-agglomerated particles were monodispersed with uniform shells. This indicates a slower agglomeration process at lower $\mathrm{pH}$ $(\mathrm{pH}=11)$. A very thin shell was obtained after one step layer deposition (Figure 5a). On the other side, a homogenous shell with average thickness of $\sim 50 \mathrm{~nm}$ was obtained after four-step layer deposition (Figure 5b).

It has been observed that the thickness of $50 \mathrm{~nm}$, obtained by a four-step deposition process at $\mathrm{pH}=11$, allowed the separation of silica core/cobalt ferrite shell particles from
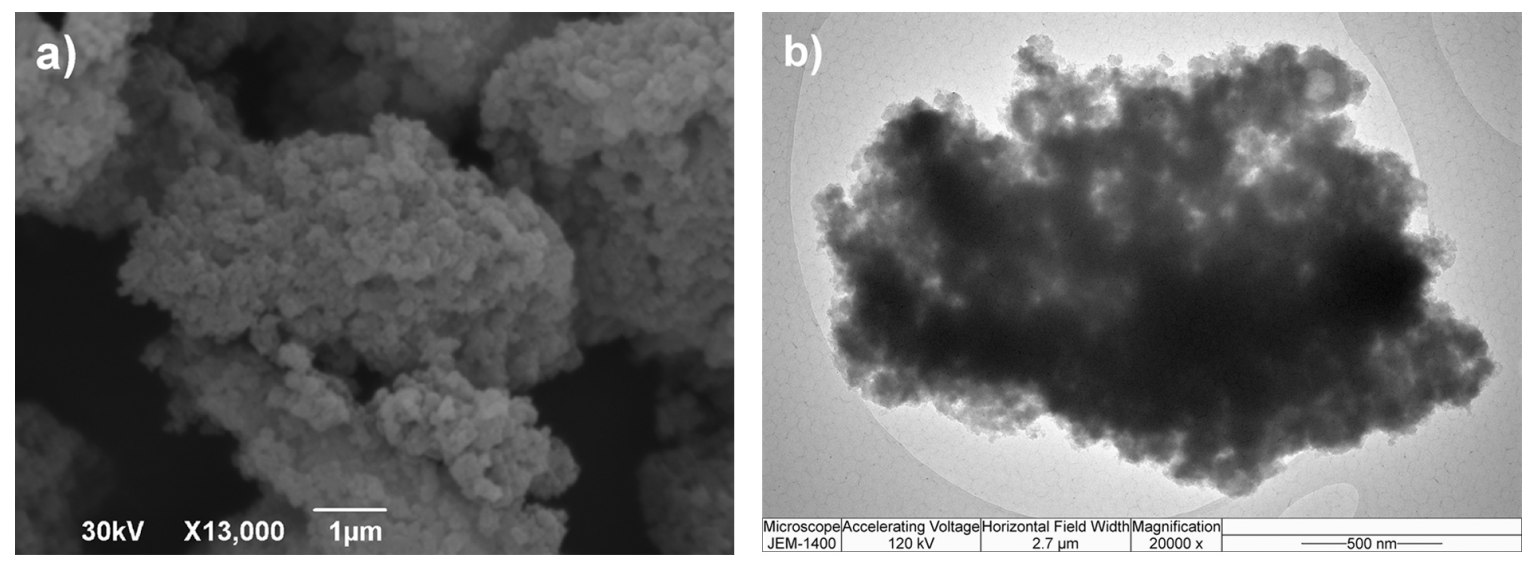

Figure 4. SEM (a) and TEM (b) micrographs of silica core/cobalt ferrite shell particles obtained at $\mathrm{pH}=15$ (sample CF2-15). 
aqueous solution using a N45 NdFeB magnet (Figure 6). Taking this into account, and since the further increase in the number of deposits would result in a more intense response to the magnetic field, a four-stage deposition was considered sufficient.

Aggregation of the silica core/cobalt ferrite shell particles at $\mathrm{pH}=15$ and absence of aggregation were also confirmed by the particle size distribution shown on Figure 7 . There is unimodal distribution for CF4-11 sample obtained at $\mathrm{pH}$ $=11$, representing the separate silica core/cobalt ferrite shell particles. On the other hand, there is a bimodal particle size distribution for CF2-15 sample obtained at $\mathrm{pH}=15$, showing a high intensity peak at $5 \mu \mathrm{m}$, which represents aggregated silica core/cobalt ferrite shell particles.

EDS analysis with chemical mapping of the silica core/ cobalt ferrite shell particles obtained at $\mathrm{pH}=15$ (a,c) and $\mathrm{pH}=11(\mathrm{~b}, \mathrm{~d})$ is shown on Figure 8. This revealed that these layers are composed of uniformly distributed iron, cobalt, oxygen and silicon atoms. The presence of sodium in the sample obtained at extremely high $\mathrm{pH}$ value $(\mathrm{pH}=15)$ is due to high concentration of sodium hydroxide used during precipitation process. The presence of carbon is due to functionalization with PDDA. The chlorine atoms come from sodium chloride used in funcionalization with PDDA. In addition, EDS mapping of the sample surface showed that $\mathrm{Fe}$ and $\mathrm{Co}$ atoms are uniformly distributed over the sample surface.

Figure 9a shows X-ray pattern of the silica core particles (red lines) and ferrite particles (black lines) obtained by coprecipitation of $\mathrm{Co}^{2+}$ and $\mathrm{Fe}^{3+}$ ions at $\mathrm{pH}=15$ in the presence of equimolar amount of citric ions. X-ray pattern of the silica core particles shows a broad reflection peak centered at about $2 \theta=24^{\circ}$, which is a characteristic of amorphous silica ${ }^{23}$. On the other hand, the cobalt ferrite particles revealed an ill-crystallized material approaching the amorphous state. Three weak and very broad peaks, at
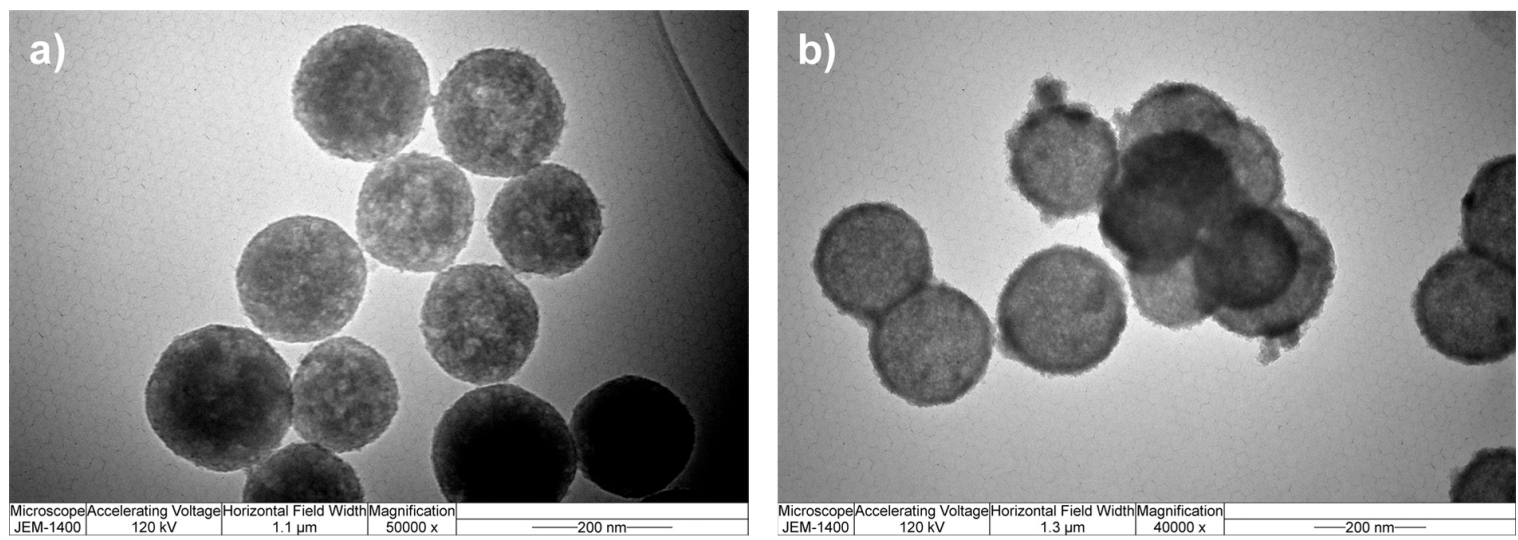

Figure 5. TEM micrographs of silica core/cobalt ferrite shell particles obtained at $\mathrm{pH}=11$ by one step (a) and four step (b) layer deposition.
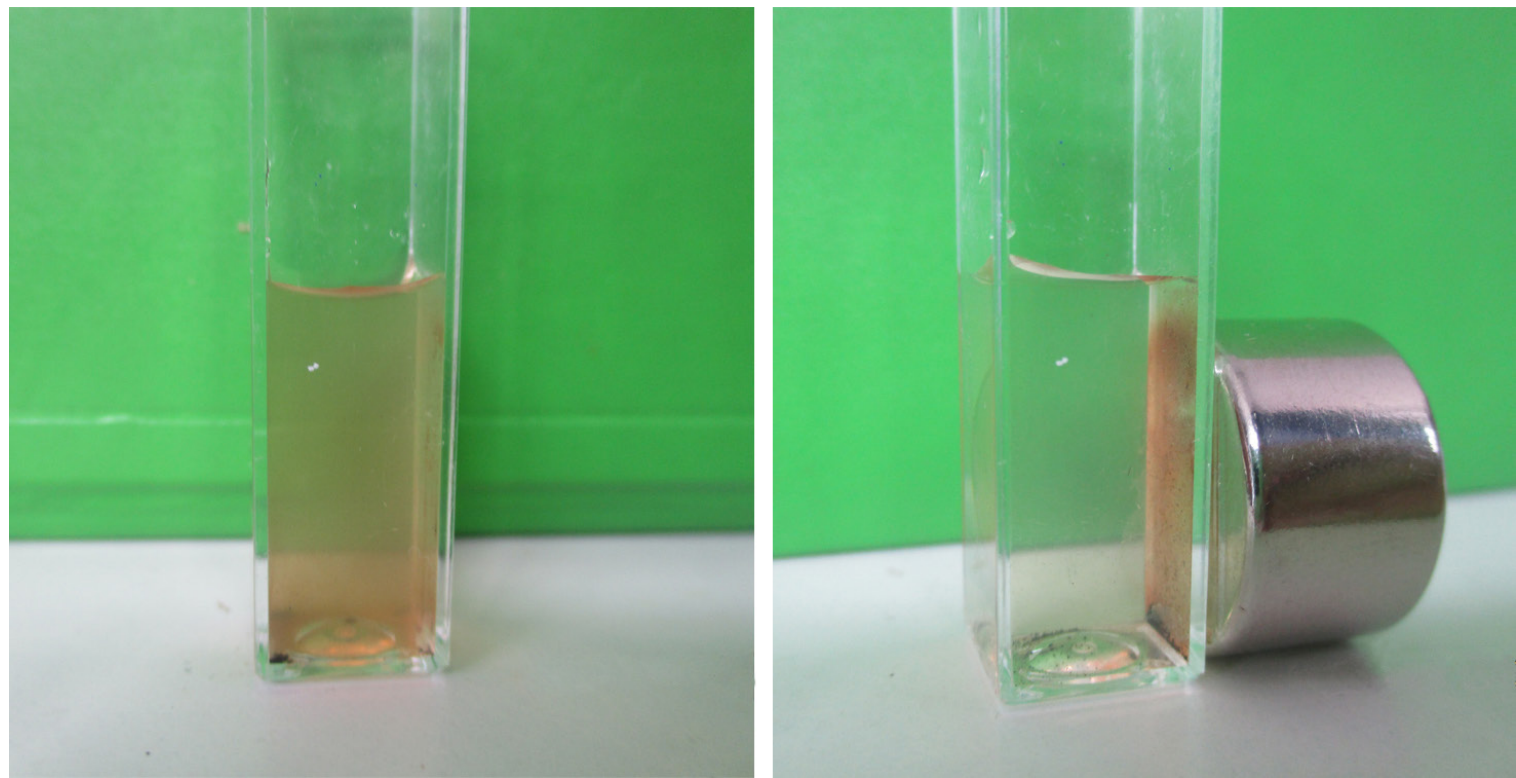

Figure 6. Magnetic separation of fourlayered core/shell particles (sample CF4-11) from aqueous solution by a N45NdFeB magnet. 
$2 \theta=35.43^{\circ}(311), 43.05^{\circ}(400)$ and $62.58^{\circ}(440)$ represent the most intense diffraction peaks of cobalt ferrite particles with a cubic spinel structure ${ }^{24}$.

$\mathrm{X}$-ray diffraction patterns of the monolayered (sample CF1-11; black lines) and four-layered silica core/cobalt ferrite shell particles (sample CF4-11; red lines) are shown in Figure 9b. The shell thickness affects the amplitude of XRD peaks (Figure 9b). Diffraction peak which is a characteristic of amorphous silica is clearly visible in X-ray pattern of the monolayered silica core/cobalt ferrite shell particles

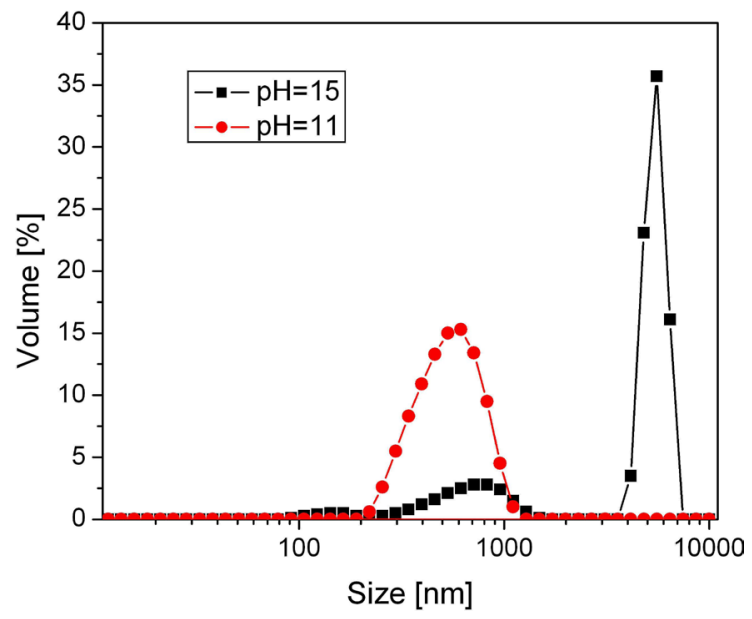

Figure 7. Particle size distribution of silica core/cobalt ferrite shell particles obtained at $\mathrm{pH}=15$ and $\mathrm{pH}=11$.
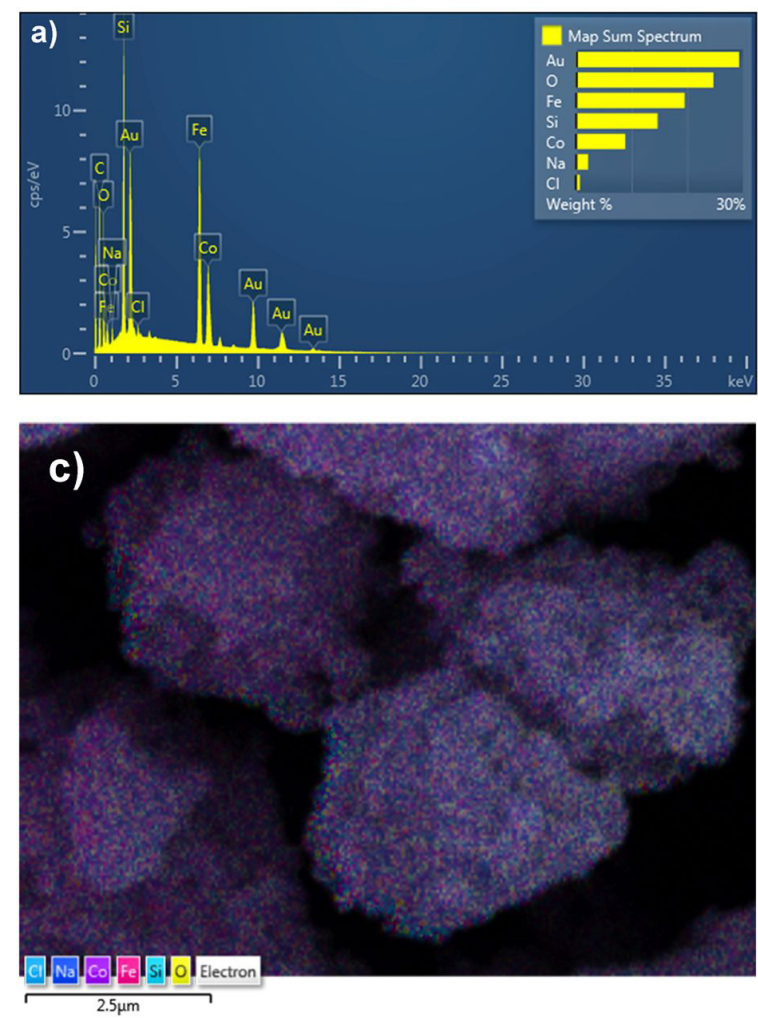

(sample CF1-11). On the other hand, this diffraction peak is unexpressed in X-ray pattern of the four-layered silica core/cobalt ferrite shell particles (sample CF4-11), while the diffraction peaks located at (311) and (440) are expressed.

After the heat treatment at $600^{\circ} \mathrm{C}$, the crystallinity of the monolayered and four-layered cobalt ferrite shell was more pronounced with diffraction peaks located at (311), (400), (511) and (440) for the sample CF1 (Figure 10a), as well (220), (311), (400), (511), (440) and (533) for the sample CF4 (Figure 10b).

Magnetization vs temperature curves of the pressed powder (sample CF4-11) are shown in Figure 11. The results of the magnetization measurements indicate that, after the first heating of the sample up to a temperature of $320^{\circ} \mathrm{C}$, the magnetization of the cooled sample was $M_{1}=0.16 \mathrm{Am}^{2} / \mathrm{kg}$ and was $14 \%$ higher than the initial magnetization obtained before heating $\left(\mathrm{M}_{\mathrm{o}}=0.14 \mathrm{Am}^{2} / \mathrm{kg}\right)$. After the heating of the same sample up to a temperature of $420^{\circ} \mathrm{C}$, the magnetization of the cooled sample was $\mathrm{M}_{2}=0.17 \mathrm{Am}^{2} / \mathrm{kg}$ and was $21.4 \%$ higher, relative to the initial magnetization obtained before heating $\left(\mathrm{M}_{\mathrm{o}}\right)$. After heating of the same sample up to a temperature of $600{ }^{\circ} \mathrm{C}$, the magnetization of the cooled sample was $\mathrm{M}_{3}=0.13 \mathrm{Am}^{2} / \mathrm{kg}$ and was $7 \%$ lower, relative to the initial magnetization obtained before heating $\left(\mathrm{M}_{\mathrm{o}}\right)$.

The increase in magnetization of the cooled sample obtained after heating up to a temperature of $320^{\circ} \mathrm{C}$ and $420^{\circ} \mathrm{C}$, respectively, is caused by a process of structural relaxation of the powder.

It should be noticed that, the as-synthesized powder contains a certain density of defects and mechanical microstresses,
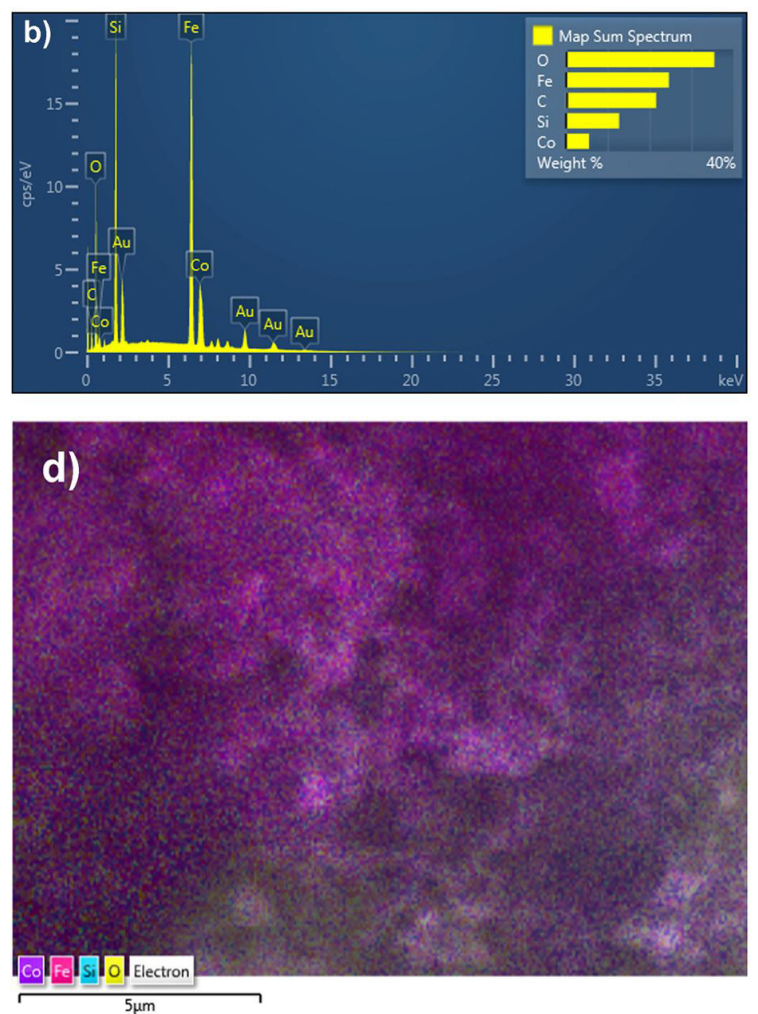

Figure 8. EDS spectrum and chemical mapping of the sample CF2-15 (a, c) and CF4-11 (b, d). 
a)

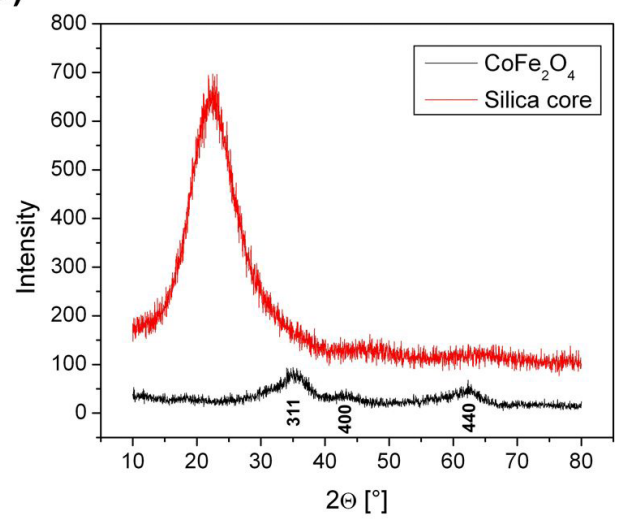

b)

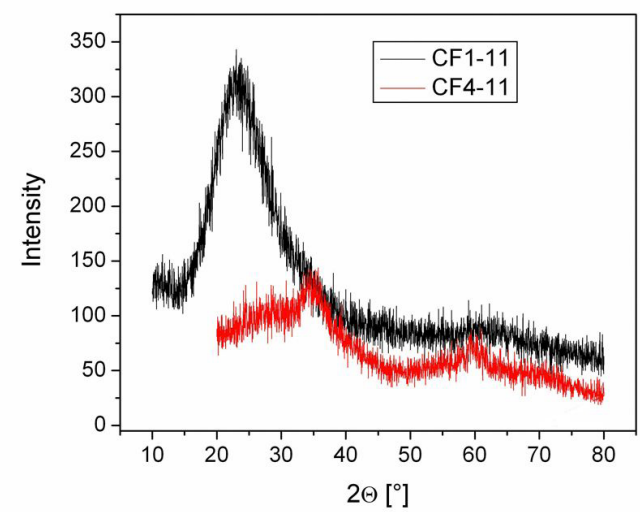

Figure 9. X-ray diffraction patterns: a) silica core particles $(\mathrm{C})$ and cobalt ferrite particles $\left(\mathrm{CoFe}_{2} \mathrm{O}_{4}\right)$; b) monolayered $\left(\mathrm{CF}_{1}-11\right)$ and fourlayered (CF4-11) silica core/cobalt-ferrite shell particles obtained at $\mathrm{pH}=11$.

a)

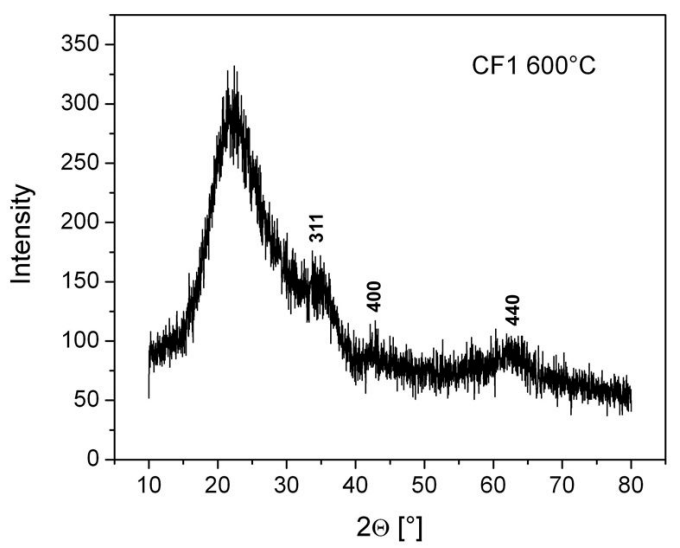

b)

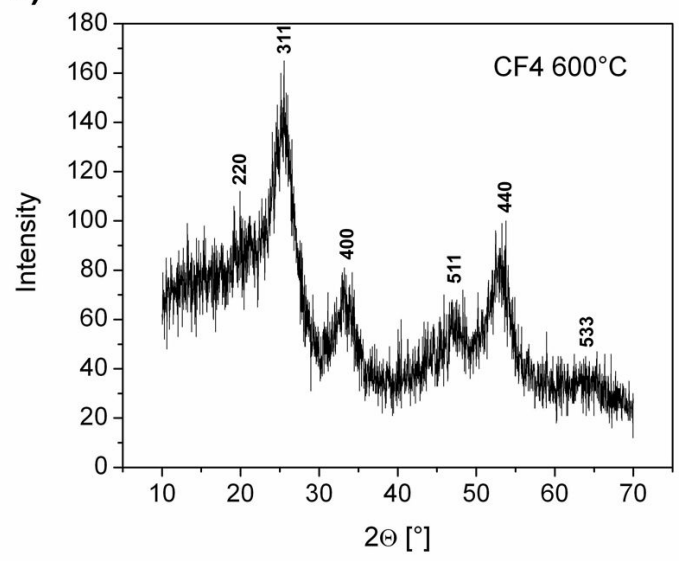

Figure 10. X-ray diffraction patterns of samples calcined at $600^{\circ} \mathrm{C}$ : a) silica core/monolayered cobalt ferrite (CF1-11); b) and silica core/ four-layered cobalt ferrite particles (CF4-11).

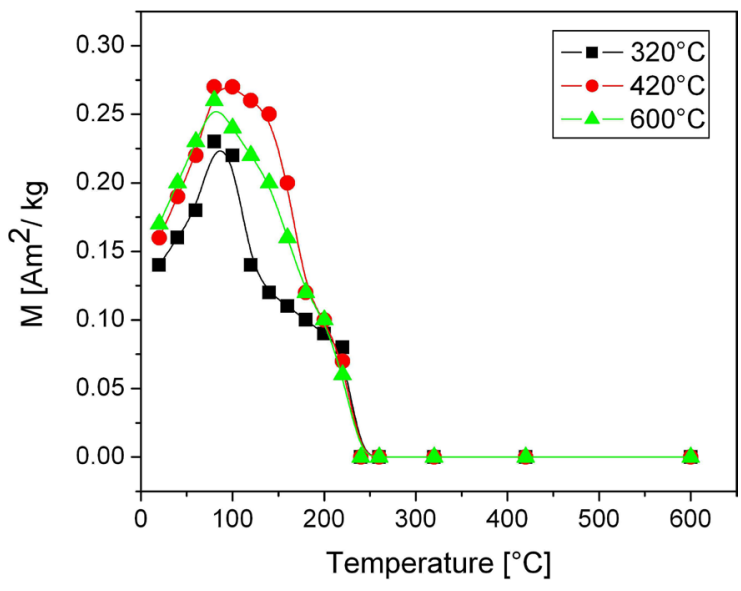

Figure 11. The dependence of magnetization vs. temperature of the pressed powder (sample CF4-11). which interfere the orientation of the magnetic domains in the applied magnetic field. The heating process influenced the structural relaxation of the ferrite shells and resulted in annihilation of defects and mechanical microstresses. After heating the sample to $420^{\circ} \mathrm{C}$, a relaxed amorphous structure is obtained, whereby the system changes from a less stable to a more stable structural state. The relaxed amorphous structure of the powder provides easier movement of the magnetic domain walls and their better orientation in the applied magnetic field, which consequently resulted in increased magnetization of the sample.

Heating the sample to $600{ }^{\circ} \mathrm{C}$ caused the amorphous phase crystallization process (XRD patterns shown on Figure 10), which resulted in a decrease in magnetization of about $7 \%$ compared to the initial value of magnetization before the first heating. The measurement results show that 
the Curie temperature did not change after heating thus remaining $240^{\circ} \mathrm{C}$.

\subsubsection{Deposition of mesoporous silica layer onto silica core/ferrite shell particles}

The silica core/ferrite shell particles (sample CF4-11) were used as templates for deposition of silica nanoparticles generated by slow addition of sulphuric acid into highly basic sodium silicate solution. Silica nanoparticles were generated at basic conditions and, in order to allow electrostatic deposition of generated silica nanoparticles on the surface of silica core/ ferrite shell particles, the latter were functionalized with PDDA. As shown in Table 1, the zeta potential of PDDA functionalized silica core/ferrite shell particles (sample CF4-p) was $27.6 \mathrm{mV}$, while the zeta potential of the sample obtained after deposition of silica layer onto PDDA-functionalized silica core/ferrite shell particles was $-20 \mathrm{mV}$. This indicates that the silica layer is deposited around positively charged PDDA-functionalized ferrite shell.

The formation of the external silica layer (generated from highly basic sodium solution) around silica core/ferrite shell particles, obtained from highly basic sodium silicate solution, was also confirmed by SEM and TEM micrographs (Figure 12). The SEM and TEM micrographs show small aggregates composed from several core shell-particles and large aggregates with average size of about $6 \mu \mathrm{m}$. This indicates that the deposited silica layer shows tendency to form networks near the gel point resulting in aggregate formation ${ }^{17}$. This is in a correlation with a bimodal particle size distribution (Figure 13 ) with a peak at $1 \mu \mathrm{m}$ representing a small size aggregates, and a peak at $6 \mu \mathrm{m}$, representing bigger aggregates. TEM micrograph (Figure 12b) shows small aggregate composed of several aggregated core-shell particles with continuous silica shell. On the other hand, the silica shell was mesoporous with non-uniform thickness ranging from 40 to $100 \mathrm{~nm}$ (Figure 12c).

As it was shown in our previous work ${ }^{17}$, the nitrogen adsorption-desorption isotherms of the silica particles obtained from sodium silicate solution at $80{ }^{\circ} \mathrm{C}$ belong to Type IV, indicating that these particles have a mesoporous structure with the average pore size of $\sim 24 \mathrm{~nm}$.

\subsubsection{Immobilization of enzymes onto mesoporous silica layer}

The effect of the substrate concentration on the initial velocity of the free and immobilized enzyme is shown on Figure 14. The activity of enzyme was significantly affected by immobilization onto mesoporous silica layer of core/shell particles (sample CF4-S). The initial velocity of the free and immobilized lipase was investigated at different substrate concentrations ranging from 0.55-6.6 mM. The activity of immobilized lipase was lowered by 13 -fold compared with a native form. The activity of lipase immobilized inside of

Table 1. Zeta potential (measured at $\mathrm{pH}=6.5$ ) of PDDA functionalized silica core/ferrite shell particles (sample CF4-p) and silica core/ferrite shell particles with deposited external silica layer (sample CF4-S).

\begin{tabular}{ccc}
\hline Sample & CF4-p & CF4-S \\
\hline Zeta potential $[\mathrm{mV}]$ & 27.6 & -20.1 \\
\hline
\end{tabular}

silica layer (sample CF4-S) was about $4.6 \mu \mathrm{mol} / \mathrm{mg}$ min at initial substrate concentration of $6.6 \mathrm{mmol} / \mathrm{dm}^{3}$, while the activity of native one was about $62 \mu \mathrm{mol} / \mathrm{mg} \mathrm{min}$ at the same concentration. The activity of the lipase immobilized onto the silica shell was decreased due to the limited diffusion of the substrate, which was caused by the internal mass transfer resistance. This resistance occurs in interstitial pores of mesoporous silica layer and this problem could be solved by increasing the silica shell pore size.

The effect of $\mathrm{pH}$ on the activity of native and immobilized enzyme is shown in Figure 15. The immobilized lipase shows a broader $\mathrm{pH}$ activity profile compared to the native lipase. The immobilized lipase possessed more than $90 \%$
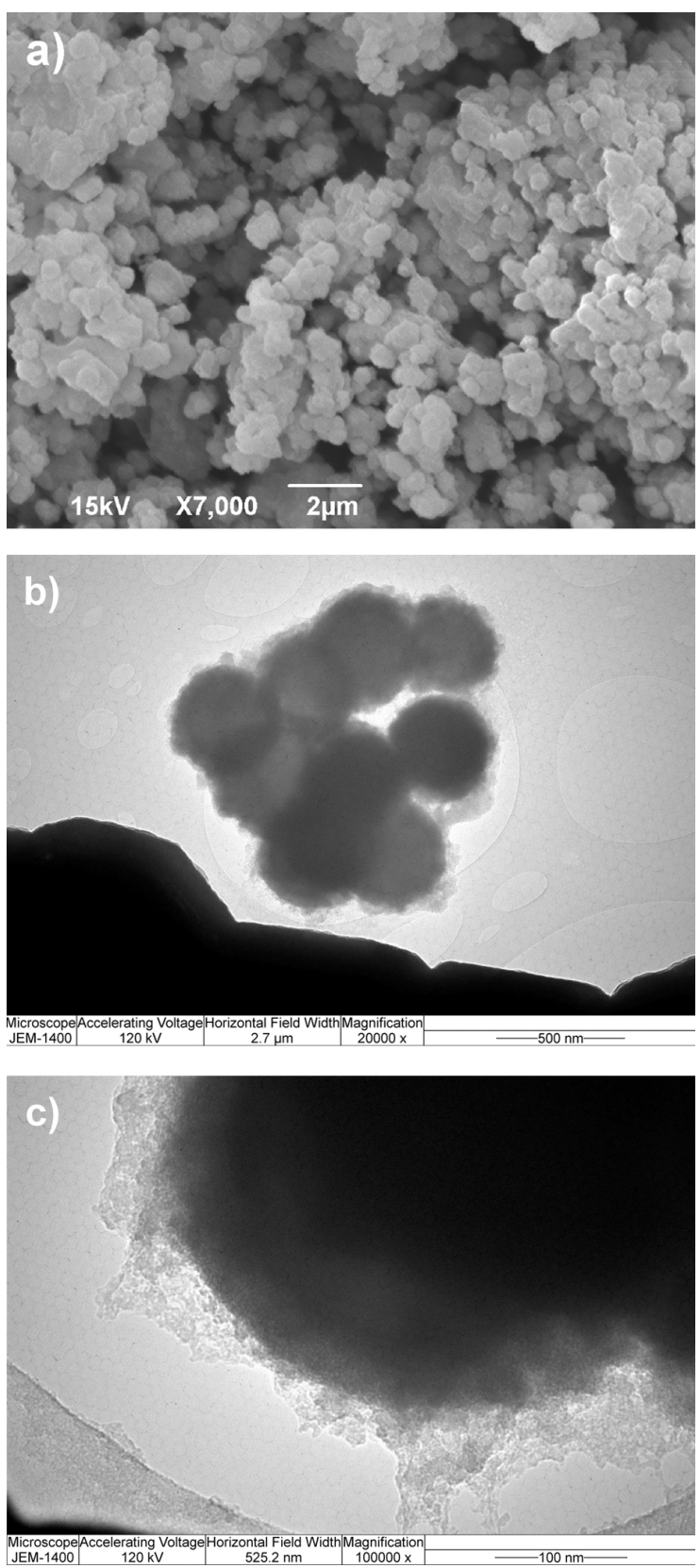

Figure 12. SEM (a) and TEM (b, c) micrographs of silica core/ four-layered ferrite/silica shell (sample CF4-S). 


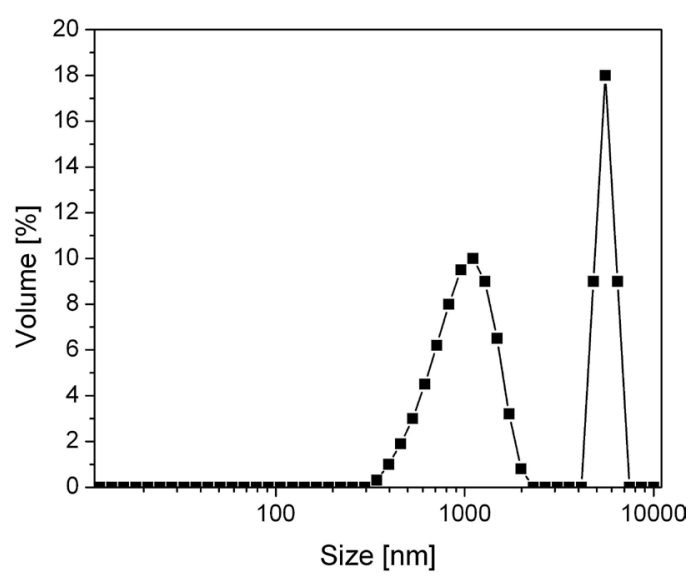

Figure 13. Particle size distribution of silica core/ferrite shell particles with deposited external silica layer (sample CF4-S).

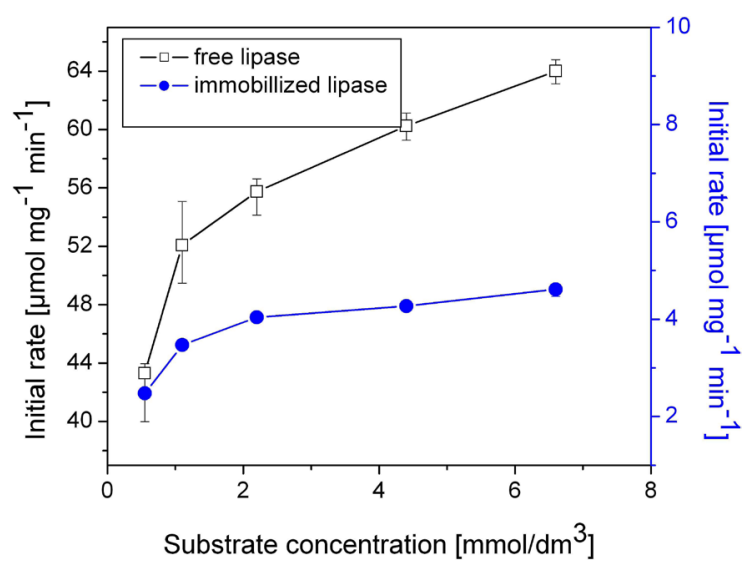

Figure 14. The effect of the substrate concentration on the initial velocity at $28^{\circ} \mathrm{C}$ : free lipase (left y-axis) and lipase immobilized onto mesoporous silica layer (right y-axis).

relative activity in the $\mathrm{pH}$ range $7.0-10.0$. The higher relative activities might be attributed to the multipoint attachment of lipase to mesoporous silica shell, which buffered variability of enzyme molecules when the $\mathrm{pH}$ was changed ${ }^{25}$.

Reusability of enzymes is an important factor for their industrial application. Reusability of CF4-S-enzyme composite was studied for ten cycles (Figure 16). The relative immobilized enzyme activity inreaction medium slowly decreased from $100 \%$ (initial cycles) to $80 \%$ (after the tenth cycle).

To examine the potential effect of enzyme leaching from the material, the activity of the supernatant, obtained after mixing the immobilized enzyme (previously used in five reaction cycles) in the phosphate buffer, was investigated. The activity of supernatant was examined by its incubation in $1.1 \mathrm{mM}$ substrate solution. No supernatant activity was detected, indicating that there was no desorption of the enzyme from the support, leading to a conclusion that desorption of the enzyme did not cause a decrease in the activity of the composite material, as it was the case with immobilization of enzyme into mesoporous silica layer by physical adsorption ${ }^{17}$. The results have shown that, since the immobilized lipase

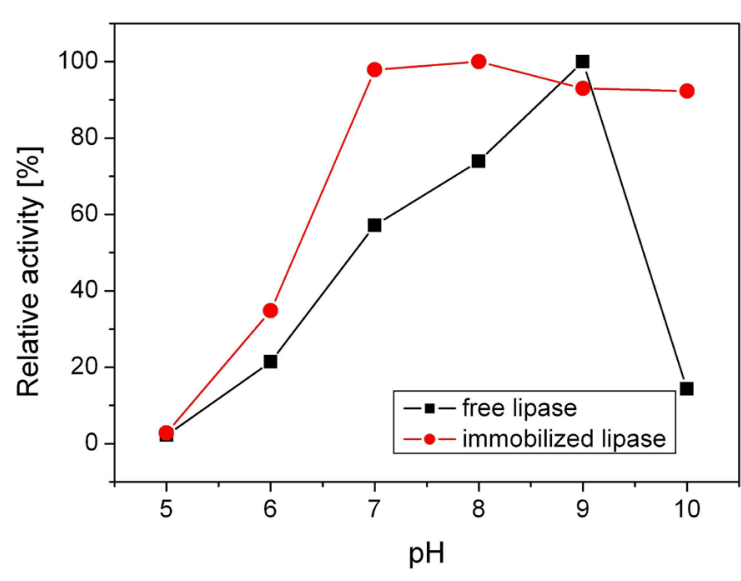

Figure 15. The effect of $\mathrm{pH}$ on the activity of native and immobilized lipase.

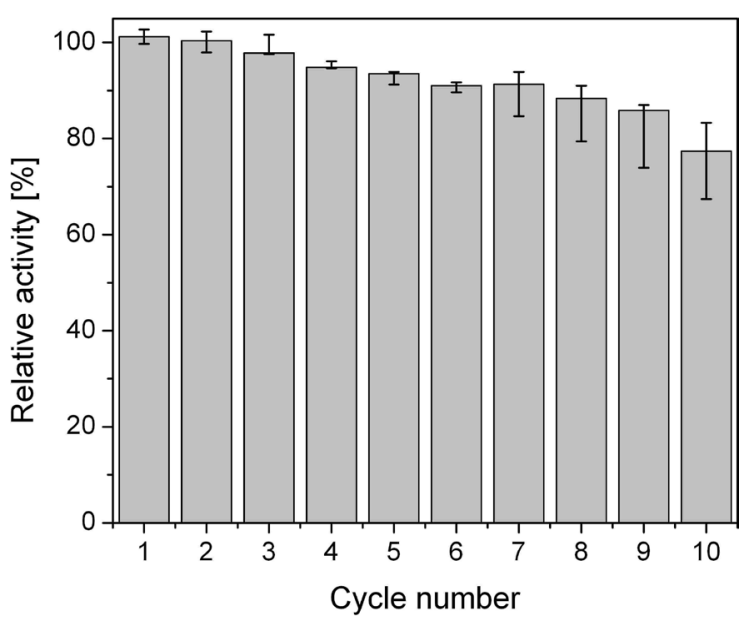

Figure 16. Recycling diagram of immobilized enzymes.

has good recyclability, materials with mesoporous silica layer assembled onto silica core/ferrite shell particles are suitable for covalent immobilization of lipase.

Temperature affects the stability and activity of free and immobilized enzymes. Figure 17 shows relative activities of the native and immobilized enzymes, determined after thermal treatment of the enzyme at temperatures of 45, 60 and $75^{\circ} \mathrm{C}$, respectively. The immobilized enzymes, retaining up to $30 \%$ activity at $75^{\circ} \mathrm{C}$, showed better thermal stability than the native ones, which lost all activity after thermal treatment at $75^{\circ} \mathrm{C}$. The relative activities of the immobilized enzymes, obtained after thermal treatment at 45 and $60^{\circ} \mathrm{C}$, were 88 and $56 \%$, respectively, while the relative activities of native enzymes were 71 and $24 \%$, respectively. The native enzyme was completely inactivated after a treatment carried out at $75{ }^{\circ} \mathrm{C}$, while the relative activity of immobilized enzyme was $30 \%$ at the same temperature.

These results show that the thermal stability of lipase covalently immobilized inside the external mesoporous silica layer is higher than the stability of the free enzyme. Enhanced thermal stability of immobilized enzyme might be 


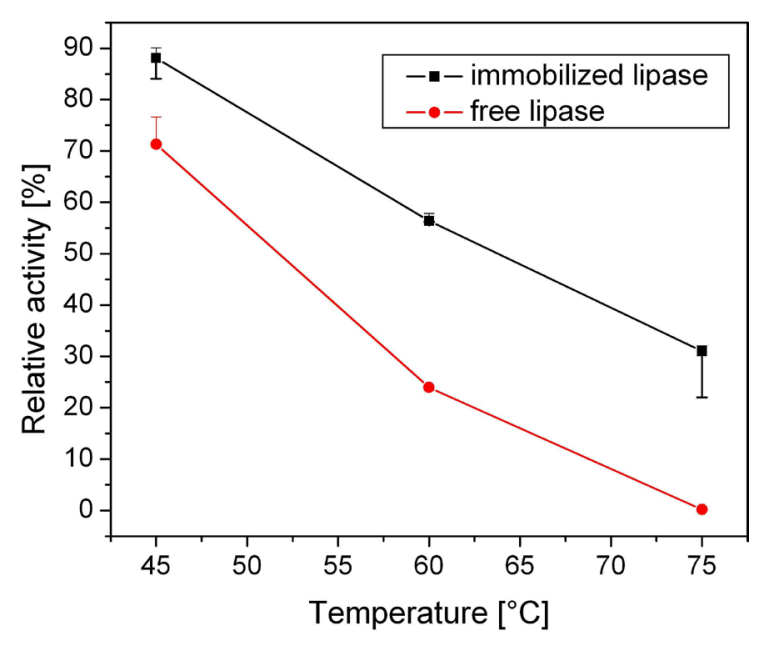

Figure 17. Effect of temperature on thermal stability of the native and immobilized enzyme.

related to the presence of more covalent cross-links between glutaraldehyde bound onto the amino functionalized silica layer and enzyme molecules, which result in conformational stabilization of lipase in support.

As a result of all this, the use of spherical silica particles as templates for deposition of cobalt ferrite allowed formation of homogenous and uniform cobalt ferrite shell.

Furthermore, the thickness of ferrite shell increases with the increase of deposition number, while the deposition of silica layer onto prepared silica core/cobalt ferrite shell particles results in formation of magnetic mesoporous composite spheres used for enzyme immobilization. Functionalized external mesoporous silica layer allowed enzyme immobilization inside mesopores providing the enzyme stability. On the other hand, internal magnetic shell provides recovery of immobilized enzymes by magnetic separation.

\section{Conclusion}

Four-step deposition of ferrite nanoparticles (obtained by co-preciptation of $\mathrm{Co}^{2+}$ and $\mathrm{Fe}^{3+}$ ionsat $\mathrm{pH}=11$ ) performed on PDDA functionalized silica core and previously deposited ferrite layer, respectively, resulted in formation of uniform four-layered ferrite shell with average shell thickness of about $50 \mathrm{~nm}$. However, co-precipitation of $\mathrm{Co}^{2+}$ and $\mathrm{Fe}^{3+}$ ions at $\mathrm{pH}=15$ resulted in self-aggregation of core-shell particles. X-ray diffraction patterns of as-synthesized silica core/cobalt ferrite shell particles showed amorphous structure, while thermal treatment at $600^{\circ} \mathrm{C}$ resulted in formation of crystalline regions having diffraction peaks characteristic to cobalt ferrite with a cubic spinel structure. Heat treatment of silica core/cobalt ferrite shell particles up to $420^{\circ} \mathrm{C}$ improved magnetization by $21.4 \%$ relative to the initial magnetization obtained before heating. Silica core/four-layered ferrite shell particles were used as a template for deposition of mesoporous silica layer, which was used as a host for covalent immobilization of lipase. The immobilized enzyme was not prone to leaching and had a decrease in relative activity by only $20 \%$ after ten reaction cycles. The immobilized lipase showed better thermal stability than the native one, retaining up to $30 \%$ activity at $75^{\circ} \mathrm{C}$, while the native enzyme completely lost its activity at this temperature. The immobilized lipase also showed a broader $\mathrm{pH}$ activity profile compared to the native lipase retaining more than $90 \%$ relative activity in the $\mathrm{pH}$ range $7.0-10.0$.

The future investigations will be focused on improving the magnetization of core/shell composite particles, as well as improving the activity of immobilized lipase by increasing the silica shell pore size.

\section{Acknowledgments}

This work was financially supported by the Ministry of Education, Science and Technological Development of the Republic of Serbia, project ref. number 451-03-68/202014/2000088 and project ref. number 451-03-9/2021-14. COST CA19124 Project is also highly acknowledged.

\section{References}

1. Xu E, Campanella OH, Xingqian Y, Jin Z, Liu D, BeMiller $J N$. Advances in conversion of natural biopolymers: a reactive extrusion (REX)-enzyme-combined strategy for starch/proteinbased food processing. Trends Food Sci Technol. 2020;99:16780.

2. Rehman A, Ali Raz A, Masood R. Optimization of lipase activity under various chemo-physical conditions for hydrolysis of polyester fabric using multiple statistical approaches. J Textil Inst. 2020;111:826-34.

3. Giannakopoulou A, Gkantzou E, Polydera A, Stamatis H. Multienzymatic nanoassemblies: recent progress and applications. Trends Biotechnol. 2020;38:202-16.

4. Kanmani P, Aravind J, Kumaresan K. An insight into microbial lipases and their environmental facet. Int J Environ Sci Technol. 2015;12:1147-62.

5. Bilal M, Asgher M, Cheng H, Yan Y, Iqbal HMN. Multi-point enzyme immobilization, surface chemistry, and novel platforms: a paradigm shift in biocatalyst design. Crit Rev Biotechnol. 2019;39:202-19

6. Lu A-H, Salabas EL, Schüth F. Magnetic nanoparticles: synthesis, protection, functionalization, and application. Angew Chem Int Ed. 2007;46(8):1222-44

7. Jiang X-P, Lu T-T, Liu C-H, Ling X-M, Zhuang M-Y, Zhang $\mathrm{J}-\mathrm{X}$, et al. Immobilization of dehydrogenase onto epoxyfunctionalized nanoparticles for synthesis of (R)-mandelic acid. Int J Biol Macromol. 2016;88:9-17.

8. Zhuang M-Y, Zhou Q-L, Wang X-Y, Zhang J-X, Lan X, Wang $\mathrm{R}$, et al. Immobilization of lipase onto dopamine functionalized magnetic nanoparticles. Nanosci Nanotechnol Lett. 2016;8:2514.

9. Zhuang M-Y, Jiang X-P, Ling X-M, Xu M-Q, Zhu Y-H, Zhang Y-W. Immobilization of glycerol dehydrogenase and NADH oxidase for enzymatic synthesis of 1,3-dihydroxyacetone with in situ cofactor regeneration. J Chem Technol Biotechnol. 2018;93:2351-8.

10. Zhuang M-Y, Wang C, Xu M-Q, Ling X-M, Shen J-J, Zhang Y-W. Using concanavalinA as a spacer for immobilization of E. coli onto magnetic nanoparticles. Int J Biol Macromol. 2017;104:63-9.

11. El-Toni AM, Habila MA, Labis JP, Al Othman ZA, Alhoshan M, Elzatahry AA, et al. Design, synthesis and applications of core-shell, hollow core, and nanorattle multifunctional nanostructures. Nanoscale. 2016;8:2510-31.

12. Wei L, Fang Z, Xiao-Yun Z, Yue L, Xiang-Yu W, Xi-Ming $\mathrm{X}$, et al. Preparation of Magnetic $\mathrm{Fe}_{3} \mathrm{O}_{4} @ \mathrm{SiO}_{2}$ Nanoparticles for 
Immobilization of Lipase. J Nanosci Nanotechnol. 2014;14:306872.

13. Wan D, Yan C, Liu Y, Zhu K, Zhang Q. A novel mesoporous nanocarrier: integrating hollow magnetic fibrous silica with PAMAM into a single nanocomposite for enzyme immobilization. Microporous Mesoporous Mater. 2019;280:46-56.

14. Zhang T, Huang B, Elzatahry AA, Alghamdi A, Yue Q, Deng Y. Synthesis of Podlike Magnetic Mesoporous Silica Nanochains for Use as Enzyme Support and Nanostirrer in Biocatalysis. ACS Appl Mater Interfaces. 2020;12:17901-8.

15. Gao J, Kong W, Zhou L, He Y, Ma L, Wang Y, et al. Monodisperse core-shell magnetic organosilica nanoflowers with radial wrinkle for lipase immobilization. Chem Eng J. 2017;309:70-9.

16. Nikolić MP, Giannakopoulos KP, Srdić VV. Synthesis and characterization of mesoporous and superparamagnetic bilayeredshell around silica core particles. Ceram Int. 2015;4:13480-5.

17. Nikolić MP, Pavlović VB, Stanojević-Nikolić S, Srdić VV. Enzyme immobilization using two processing methods onto silica core-shell particles. Bol Soc Esp Ceram Vidr. 2021;60:243-54.

18. Nikolić MP, Giannakopoulos KP, Stamopoulos D, Moshopoulou EG, Srdić VV. Synthesis and characterization of silica core/ nano-ferrite shell particles. Mater Res Bull. 2012;47:1513-9.

19. Li Y, Wang X-Y, Jiang X-P, Ye J-J, Zhang Y-W, Zhang X-Y. Fabrication of graphene oxide decorated with $\mathrm{Fe}_{3} \mathrm{O}_{4} @ \mathrm{SiO}_{2}$ for immobilization of cellulose. J Nanopart Res. 2015;17:8.
20. Bradford M. A rapid and sensitive method for quantitationof microgram quantities of protein utilizing principle of protein dye binding. Anal Biochem. 1976;72:248-54.

21. Ristanović Z, Kalezić-Glišović A, Mitrović N, Đukić S, Kosanović D, Maričić A. The influence of mechanochemical activation and thermal treatment on magnetic properties of the $\mathrm{BaTiO}_{3}-\mathrm{FexOy}$ powder mixture. Sci Sinter. 2015;47:3-14.

22. Gustafsson H, Thorn C, Holmberg K. A comparison of lipase and trypsin encapsulated in mesoporous materials with varying pore sizes and $\mathrm{pH}$ conditions. Colloids Surf B Biointerfaces. 2011;87:464-71.

23. Alvarez A, Guzmán C, Carbone A, Saccà A, Gatto I, Pedicini $\mathrm{R}$, et al. Composite membranes based on micro and mesostructured silica: a comparison of physicochemical and transport properties. J Power Sources. 2011;196:5394-401.

24. Long NV, Yang Y, Teranishi T, Thi CM, Cao Y, Nogamie M. Related magnetic properties of $\mathrm{CoFe}_{2} \mathrm{O}_{4}$ cobalt ferrite particles synthesised by the polyol method with $\mathrm{NaBH}_{4}$ and heat treatment: new micro and nanoscale structures. RSC Advances. 2015;5:56560-9.

25. Wang X-Y, Jiang X-P, Li Y, Zeng S, Zhang Y-W. Preparation $\mathrm{Fe}_{3} \mathrm{O}_{4} @$ chitosan magnetic particles for covalent immobilization of lipase from Thermomyces lanuginosus. Int J Biol Macromol. 2015;75:44-5. 